\title{
ANALISIS PENGKAJIAN PROSES KEPERAWATAN PADA ANAK
}

\author{
Atikah Ulfah Marwa/181101106
}

\author{
ninanamanis@gmail.com
}

\begin{abstract}
Abstrak
Latar belakang : Tujuan utama asuhan keperawatan anak yang dihospitalisasi adalah meminimalkan munculnya masalah pada perkembangan anak. Perawat yang melibatkan anak dalam aktivitas yang sesuai dengan tingkat perkembangan akan lebih menormalkan lingkungan anak dan membantu mengurangi gangguan perkembangan anak. Tujuan : konsep dari proses keperawatan pada anak. Metode penelitian : literature review dengan cara menganalisis artikel, jurnal maupun text book. Artikel yang digunakan 14 referensi yang diterbitkan sepuluh tahun terakhir yang menggunakan google scholar, google book dan science direct. Hasil : asuhan keperawatan memiliki tahapan pemecahan masalah kesehatan pasien /klien, dimulai dari Pengkajian (Pengumpulan Data, Analisis Data dan Penentuan Masalah) Diagnosis Keperawatan, Pelaksanaan dan Penilaian Tindakan Keperawatan.. Kesimpulan : dalam melakukan proses keperawatan pada anak seharusnya dilakukan dengan tahapan-tahapan asuhan keperwatan yang sudah diterapkan.
\end{abstract}

Kata kunci : asuhan keperawatan, proses keperwatan, anak, kecemasan pada anak.

Abstract

Background: The main purpose of child care is spent on overcoming child development problems. Nurses who involve children in activities that are appropriate to the level of development will normalize the child's environment and help reduce child development. Objective: the concept of the nursing process in children. Research methods: literature review by analyzing articles, journals and textbooks. Articles used 14 references published over the last ten years using Google Scholar, Google Books and Science Direct Results: Nursing care related to solving health problems of patients / clients, starting from the Data Assessment, Data Analysis and Determination of Problems) Nursing Diagnosis, Implementation and Assessment of Nursing Measures, nursing care that has been implemented. Conclusion: in carrying out the nursing process in children should be done with nursing care stages that have been applied.

Keywords: nursing care, nursing process, children, care for children. 
PENDAHULUAN

Dokumentasi keperawatan merupakan sesuatu yang membuktikan pencatatan dan pelaporan yang dimiliki pada perawat dalam melakukan catatan keperawatan dan berguna untuk kepentingan klien, perawat dan tim kesehatan dalam memberikan pelayanan kesehatan dengan dasar komunikasi yang akurat dan baik secara tertulis dengan tanggung jawab pada perawat (Hidayat, 2007). Dalam suatu organisasi setiap orang mempunyai kepentingan dan tujuan masing-masing, bersaing untuk mencapai kepentingannya dalam organisasi tersebut. (Selanno,2014).

\section{Hospitalisasi merupakan} keadaan dimana seseorang dalam kondisi yang mengharuskan untuk mendapat perawatan dirumahsakit untuk mengatasi atau meringankan sakitnya. Hospitalisasi pada anak dapat menimbulkan kecemasan dan stress dimana hal itu diakibatkan karena adanya perpisahan, kehilangan control, ketakutan mengenai kesakitan pada tubuh, serta nyeri dimana kondisi tersebut belum pernah dialami sebelumnya (Erna setiawati dan Sundari, 2019)
Tujuan utama asuhan keperawatan anak yang dihospitalisasi adalah meminimalkan munculnya masalah pada perkembangan anak. Perawat yang melibatkan anak dalam aktivitas yang sesuai dengan tingkat perkembangan akan lebih menormalkan lingkungan anak dan membantu mengurangi gangguan perkembangan anak (Wong, 2008).

Bermain merupakan pekerjaan pada masa kanak-kanak. Ahli pekembangan anak mengakui bahwa bermain sebagai strategi koping yang penting bagi anak, hal tersebut merupakan aspek terpenting dalam kehidupan anak serta merupakan salah satu cara yang efektif dalam menurunkan stres pada anak dan juga penting untuk menyejahterakan mental anak dan emosional anak (Purwandari, Mulyono, \& Sucipto, 2010).

Bermain dapat dijadikan sebagai suatu terapi karena berfokus pada kebutuhan anak untuk mengekspresikan diri mereka melalui penggunaan mainan dalam aktivitas bermain dan dapat digunakan untuk membantu anak mengerti tentang penyakitnya. Bermain terapeutik sudah diidentifikasi sebagai intervensi yang efektif untuk persiapan anak hospitalisasi, koping, pemahaman, 
dan prosedur untuk mengurangi nyeri, dan stres karena hospitalisasi. Prosesnya dapat dilakukan dengan cara melibatkan penggunaan film, video, atau buku-buku (Alfiyanti, Hartati \& Samiasih, 2007).

Penelitian ini secara umum bertujuan untuk mengetahui konsep dari proses keperawatan pada anak. Dengan mengetahui hal ini perawat dapat mengetahu lebih dalam tentang pengkajian proses keperawatan pada anak.

\section{METODE PENELITIAN}

\begin{abstract}
Metoode penelitian yang digunakan adalah literature review dengan cara menganalisis artikel, jurnal maupun text book yang berkaitan dengan pembelajaran mahasiswa keperawatan analisi pengkajian proses keperawatan pada anak.
\end{abstract}

Artikel yang digunakan 14 referensi yang diterbitkan sepuluh tahun terakhir yang menggunakan google scholar, google book dan science direct. Dalam mencari artikel, kata kunci yang digunakan ialah analisi pengkajian proses keperawatan pada anak.

\section{HASIL DAN PEMBAHASAN}

Dari pencarian literature, dalam mengurangi kecemasan pada pasien anak dapat menjadi salah satu masalah dari proses dalam keperawatan. Pasien anak pada awalnya memiliki kecemasan saat memasuki rumah sakit karena adanya stresor berupa berpisah dengan keluarga. Perawat dapat menggunakan sikap berpikir kritis agar pasien dan klien meminimalisir kecemasaan diantara keduanya. Juga sebagai mahasiswa keperawatan mampu menguasai sikap berpikir kritis dan profesional sehingga dapat meningkatkan kualitas kesehatan pasien dan menjaga hubungan baik mitra kesehatan maupun pasien dan keluarga pasien.

Hal ini sesuai dengan teori faktor-faktor yang mempengaruhi sikap adalah pengalaman pribadi, pengaruh orang lain, kebudayan, media massa, lembaga pendidikan/ agama, faktor emosional. Untuk dapat menjadi dasar pembentukan sikap, pengalaman pribadi haruslah meninggalkan kesan yang kuat. Oleh karena itu, sikap akan mudah terbentuk apabila pengalaman pribadi ini terjadi dalam situasi yang melibatkan faktor emosional. Pengaruh kebudayaan, tanpa didasari kebudayaan telah menanamkan pada garis pengaruh 
sikap kita terhadap berbagai masalah. kebudayaan telah mewarnai sikap-sikap anggota masyaratkat, karena kebudayaanlah yang akan memberi berbagai corak dalam pengalaman individu - individu masyarakat asuhannya. Media massa, dalam pembritahuan surat kabar maupun radio atau media komunikasi lainnya, berita yang seharusnya factual disampaikan secara obyektif cenderung dipengerahui oleh sikap penulisanya, akibatnya berpengaruh terhadap sikap konsumennya (Azwar,2002.)

Pada hari pertama anak dirawat di rumah sakit, anak berada pada fase pertama yaitu fase protes. Anak masih belum merasa nyaman berada di rumah sakit. Mereka menolak kenyataan bahwa mereka harus berada di rumah sakit dengan menerima berbagai macam terapi. Belum lagi, mereka harus beradaptasi dengan lingkungan, rutinitas, dan orang-orang yang baru. Bukan lagi teman yang ada untuk mengajak bermain, akan tetapi perawat dan tim medis lain yang sering datang mengunjungi mereka dan memberikan berbagai macam prosedur yang membuat stres. Hal ini mengindikasikan bahwa anak belum melewati fase adaptasi untuk mencapai tahap penerimaan, karena tahap penerimaan ini biasanya terjadi setelah anak dirawat di rumah sakit selama beberapa hari atau dalam jangka waktu lebih dari tiga hari dan tiap anak memiliki waktu adaptasi yang berbeda-beda (Hockenberry \& Wilson, 2013).

Proses Keperawatan adalah metode asuhan keperawatan yang ilmiah, sistematis, dinamis dan terusmenerus serta berkesinambungan dalam rangka pemecahan masalah kesehatan pasien /klien, dimulai dari Pengkajian (Pengumpulan Data, Analisis Data dan Penentuan Masalah) Diagnosis Keperawatan, Pelaksanaan dan Penilaian Tindakan Keperawatan (Ali,1997)

Perawat dituntut untuk melakukan komunikasi terapeutik dalam melakukan tindakan keperawatan agar pasien dan keluarganya tahu akan tindakan apa yang akan dilakukan perawar pada pasien. Untuk mengatasinya, perawat harus memperkenalkan diri, menjelaskan tindakan yang akan dilakukan, membuat kontrak waktu untuk melakukan tindakan keperawatan selanjutnya. Kehadiran dan Sikap benar-benar ada untuk pasien adalah bagian dari 
komunikasi terapeutik, perawat tak boleh memperlihatkan ekspresi bingung yang sebaliknya, pasien akan merasa bahwa dia merupakan fokus utama perawat selama interaksi.

Agar perawat dapat berperan aktif dan terapeutik, perawat menganalisa dirinya yang meliputi kesadaran diri, klarifikasi nilai, perasaan dan mampu menjadi model perawat yang bertanggung jawab. Seluruh sikap, perilak dan pesan yang disampaikan perawat seharusnya bertujuan sebagai terapeutik untuk pasien. Analisa hubungan intim yang terapeutik perlu dilakukan untuk evaluasi perkembangan hubungan dan menentukan teknik dan ketrampilan yang tepat dalam setiap tahap untuk mengatasi masalah pasien. (Andreas, 2009)

Metodologi proses keperawatan merupakan metodologi penyelesaian masalah kesehatan klien secara ilmiah berdasarkan pengetahuan ilmiah serta menggunakan teknologi kesehatan dan keperawatan, meliputi tahapan;

1. pengkajian tahapan ini mencakup pengumpulan data,analisi/ interpretasi data tentang kondisi bio,psiko, sosio, kultural, dan spritua klien,

2. merumuskan diagnosis keperawatan, diagnosis keperawatan adalah pernyataan yang dirumuskan berdasarkan data yang terkumpul dan berpau rumusan tentang respons klien terhadap masalah kesehatan serta faktor penyebab (etiologi) yang berkontribusi terhadap timbulnya masalah yang perlu diatasi dengan tindakan/intervensi keperawatan,

3. perencanaan, perencanaan asuhan keperawata (nursing care plan) adalah acuan tertulis yang terdiri dari berbagai intervensi keperawatan yang diriencanakan dapat mengatasi diagnosis keperawatan sehingga klien dapat terpenuhi kebutuhan dasarnya. Sifat intervensi keperawatan yang dapat dilakukan perawat, yaitu bersifat bantuan, bersifat higenis, bersifat rehabilitas, bersifat suportif, bersifat preventif, bersifat observasi, dan memberikan informasi yang 
akurat dan memuaskan ruang pengobatan.

4. implementasi, merupakan bagian aktif dari asuhan keperawatan, yaitu perawat melakukan tindakan sesuai rencana. Tindakan ini bersifat intelektual, teknis, dan interpersonal berupa berbagai upaya memenuhi kebutuhan dasar klien. Tindakan keperawatan meliputi

tindakan keperawatan

observasi keperawatan

pendidikan

kesehatan/keperawan, dan

tindakan medis yang dilakukan perawat (tugas limpah)

5. evaluasi, merupakan tahap akhir dari rangkaian proses keperawatan yang berguna apakah tujuan dari tindakan keperawtan yang telah dilakukan tercapai atau perlu pendekatan lain. (Suprijitno,2004)

Diagnosa keperawatan adalah keputusan tentang respon keluarga tentang masalah kesehatan actual atau potensial, sebagai dasar seleksi intervensi keperawatan untuk mencapai tujuan asuhan keperawatan sesuai dengan kewenangan perawatan. Tahapan dalam diagnosa keperawatan keluarga sesuai dengan kewenangan perawatan antara lain: analisa data, perumusan masalah, dan prioritas masalah (Harnilawati, 2013)

\section{KESIMPULAN}

Kesimpulan dari hasil penelitian literature view analisis pengkajian proses keperawatan pada anak adalah dalam melakukan asuhan keperawatan yang memiliki beberapa tahapan seperti pengkajian, merumuskan diagnosis keperawatan, perencanaan, implementasi, dan evaluasi. Dan dalam melakukan proses keperawatan pada anak seharusnya dilakukan dengan tahapan-tahapan asuhan keperwatan yang sudah diterapkan.

\section{REFERENSI}

Aba, D. M., Hartono, B., \& Sari, S. M. (2018).

ANALISIS

PERILAKU ORGANISASI

DALAM

PENDOKUMENTASIAN

ASUHAN KEPERAWATAN

DI RUANG RAWAT INAP

CENDRAWASIH RUMAH 
SAKIT UMUM DAERAH

(RSUD)

ARI. Menara

Ilmu, 12(11).

Agustina, D. W., Santoso, W., \& Triwibowo, H. (2019). Asuhan Keperawatan Ketidakefektifan Bersihan Jalan Napas Pada Anak Dengan Pneumonia Di RSI Sakinah Mojokerto

Alfitri, R., Iswari, M., \& Kasiyati, K. (2018). Meningkatkan Pembendaharaan Kata Melalui Media Kata Bergambar bagi Anak Tunarungu. Jurnal Pendidikan Kebutuhan Khusus, 2(1), 40-45.

Brillianty, G. D., \& Wahyuni, T. (2018). Analisis Praktik Klinik Keperawatan dengan Terapi Inovasi Fisioterapi Dada terhadap Bersihan Jalan Nafas pada Pasien Pneumonia Post VP Shunt di Ruang Intensive Care Unit RSUD Abdul Wahab Sjahranie Samarinda Tahun 2018.

Hakim, N., \& Allenidekania, H. H. (2018).

EFEKTIVITAS

ASUHAN KEPERAWATAN PADA ANAK KANKER
YANG

MENGALAMI

GANGGUAN

NUTRISI

DENGAN MENGGUNAKAN

TEORI LEVINE. JURNAL

ILMIAH KEPERAWATAN

ALTRUISTIK, 1(1), 1-14.

Nur, R. R. P., Prayogi, A. S., \& Suryani, E. (2018). PENERAPAN KOMPRES HANGAT PADA ANAK DEMAM DENGAN GANGGUAN PEMENUHAN KEBUTUHAN NYAMAN DI RSUD SLEMAN (Doctoral dissertation, Poltekkes Kemenkes Yogyakarta).

Rakhmadi, D., Hariyanto, T., \& Sulasmini, S. (2018). PERBEDAAN LAMA HARI RAWAT INAP PASIEN PNEUMONIA DENGAN NON PNEUMONIA DI RUANG PERAWATAN ANAK RUMAH SAKIT UMUM DAERAH KOTABARU. Nursing News: Jurnal Ilmiah Keperawatan, 3(3).

Riyanti, E., Setyowati, S., \& Afiyanti, Y. (2019). ASUHAN KEPERAWATAN GESTATIONAL DIABETES 
MELLITUS

DENGAN

APLIKASI TEORI SELF

CARE OREM. Proceeding of The URECOL, 228-235.

Silalahi, V., \& Putri, R. M. (2018). Personal Hygiene pada Anak SD Negeri Merjosari 3. JAPI (Jurnal Akses Pengabdian Indonesia), 2(2), 15-23.

Simamora, R. H. (2019). Menjadi perawat yang: CIH'HUY. Surakarta: Kekata Publisher.

Suryani, E., \& Purwanti, K. Y. (2019). Pengenalan Game Edukasi Android Sebagai Penunjang Perkembangan Kognitif Anak. Aksiologiya: Jurnal Pengabdian Kepada Masyarakat, 3(2).

Tari, C. (2019). PENTINNGNYA PENGAPLIKASIAN BERPIKIR KRITIS BAGI PERAWAT DI IGD.

Wahyuni, N. M. H. (2018). Gambaran Asuhan Keperawatan pada Anak Bronkopneumonia dengan Gangguan Pertukaran Gas di Ruang Cilinaya RSUD Mangusada Badung Tahun
2018 (Doctoral dissertation, Jurusan Keperawatan 2018).

Wati, W. A. K., Sajidin, M., \& Hariyanto, A. (2019). ASUHAN KEPERAWATAN ANAK DENGAN MASALAH KETIDAKEFEKTIFAN

BERSIHAN JALAN NAFAS PADA PASIEN BRONKOPNEUMONIA DI RSU DR. WAHIDIN SUDIRO HUSODO MOJOKERTO.

Yugistyowati, A., \& Santoso, S. (2018). Pengetahuan Perawat Tentang Family Centered-Care Dengan Sikap Dalam Pemberian Asuhan Keperawatan Di Ruang Rawat Inap Anak. Jurnal Keperawatan Respati Yogyakarta, 5, 39-44.

Yusuf, A., Fitryasari, P. K., \& Nihayati, H. E. (2015). Buku ajar keperawatan kesehatan jiwa 